\title{
Schizotypal Personality Disorder
}

National Cancer Institute

\section{Source}

National Cancer Institute. Schizotypal Personality Disorder. NCI Thesaurus. Code C92632.

A disorder characterized by an enduring pattern of inability to establish close relationships coupled with cog nitive or perceptual distortions, odd beliefs and speech, and eccentric behavior and appearance. 